\title{
Erratum
}

\section{Erratum to "Nonlinear Dynamics in a Cournot Duopoly with Different Attitudes towards Strategic Uncertainty"}

\author{
Luciano Fanti, ${ }^{1}$ Luca Gori, ${ }^{2}$ and Mauro Sodini ${ }^{1}$ \\ ${ }^{1}$ Department of Economics and Management, University of Pisa, Via Cosimo Ridolfi 10, 56124 Pisa, Italy \\ ${ }^{2}$ Department of Law, University of Genoa, Via Balbi 30/19, 16126 Genoa, Italy \\ Correspondence should be addressed to Luca Gori; luca.gori@unige.it
}

Received 12 March 2014; Accepted 2 April 2014; Published 22 April 2014

Copyright (c) 2014 Luciano Fanti et al. This is an open access article distributed under the Creative Commons Attribution License, which permits unrestricted use, distribution, and reproduction in any medium, provided the original work is properly cited.

Figure 4(a) in the paper entitled "Nonlinear Dynamics in a Cournot Duopoly with Different Attitudes towards Strategic Uncertainty" should appear as follows.

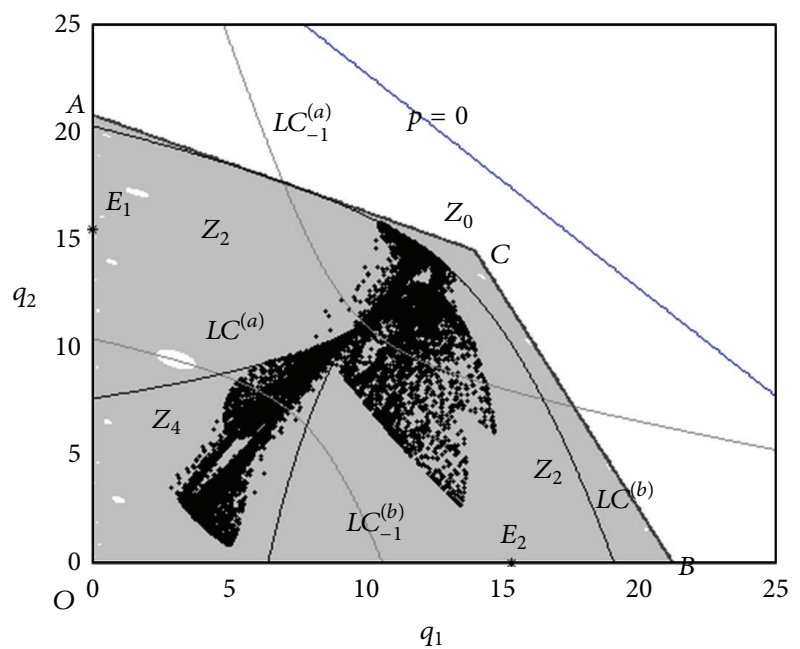

(a)

FIgure 4: Portions of the basin of attraction of trajectories that converge to invariant axes for map $M_{1}$ enter $Z_{2}$ region. This causes the appearance of several holes in the basin of attraction of the interior attractor. The blue line $p=0$ represents points in which the market price equals zero. Parameter set: $a=7.2, b=0.22, c=0.4$, $\gamma=0.9$, and $\alpha=0.427$. 


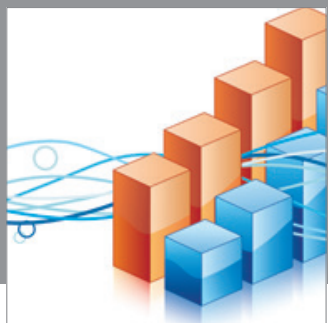

Advances in

Operations Research

mansans

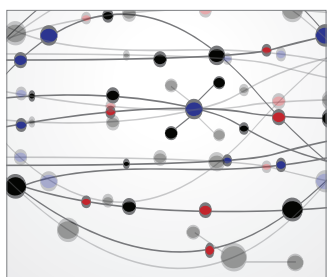

The Scientific World Journal
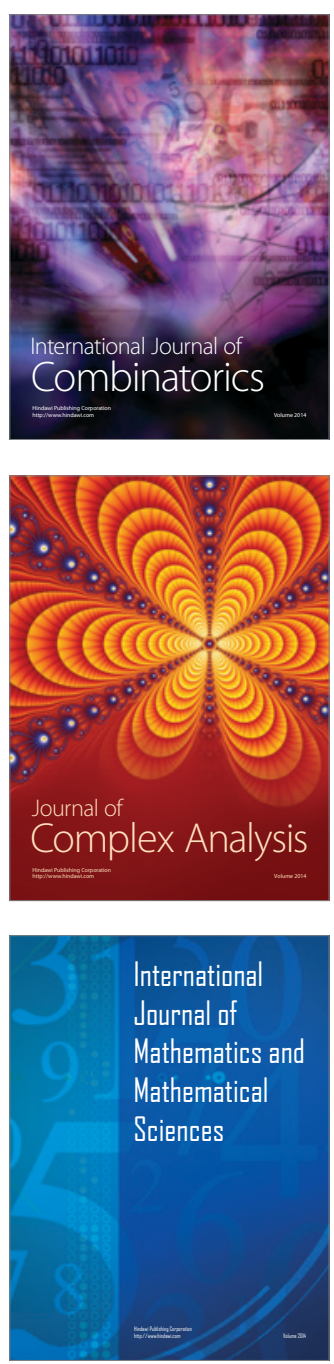
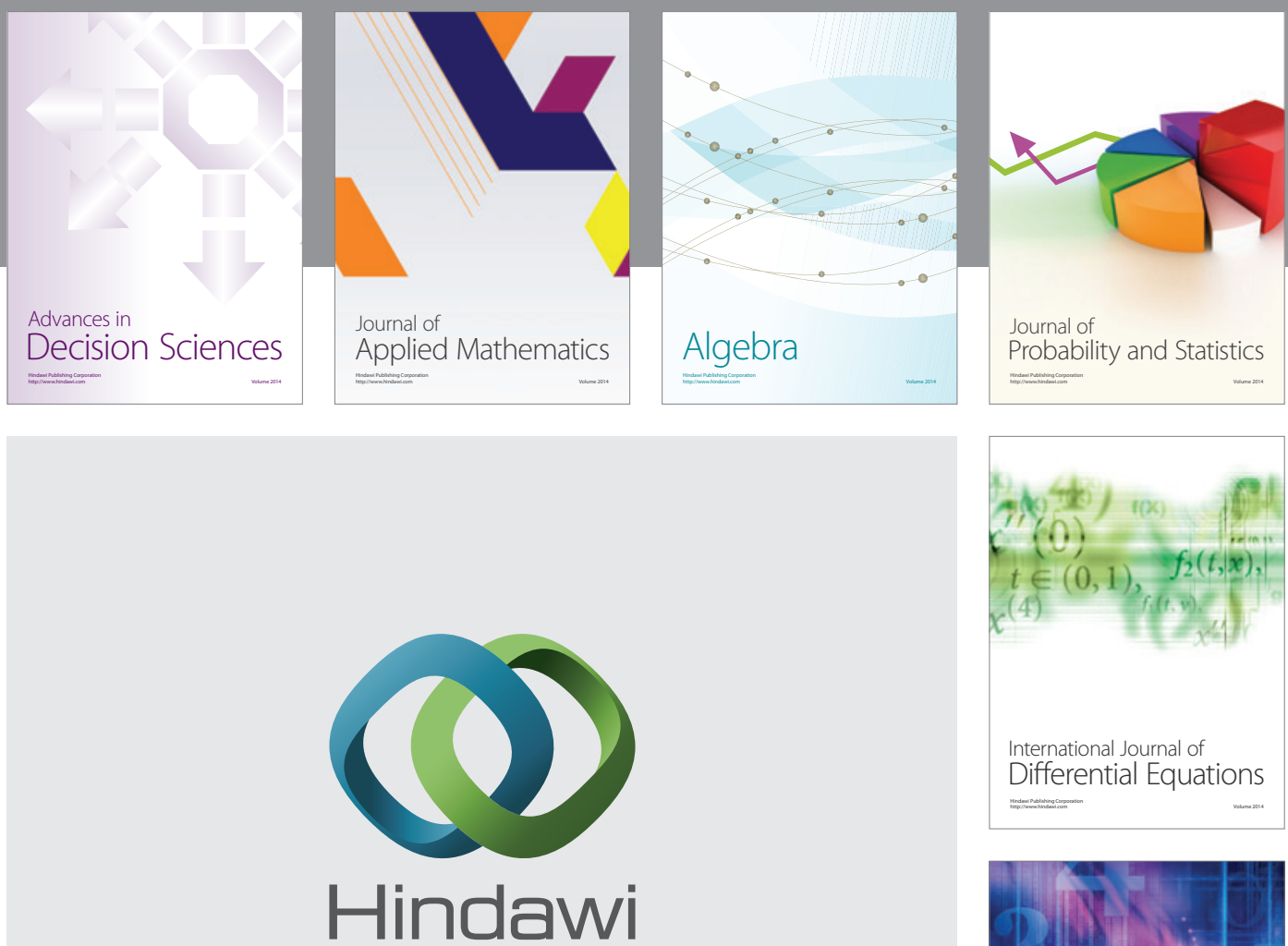

Submit your manuscripts at http://www.hindawi.com
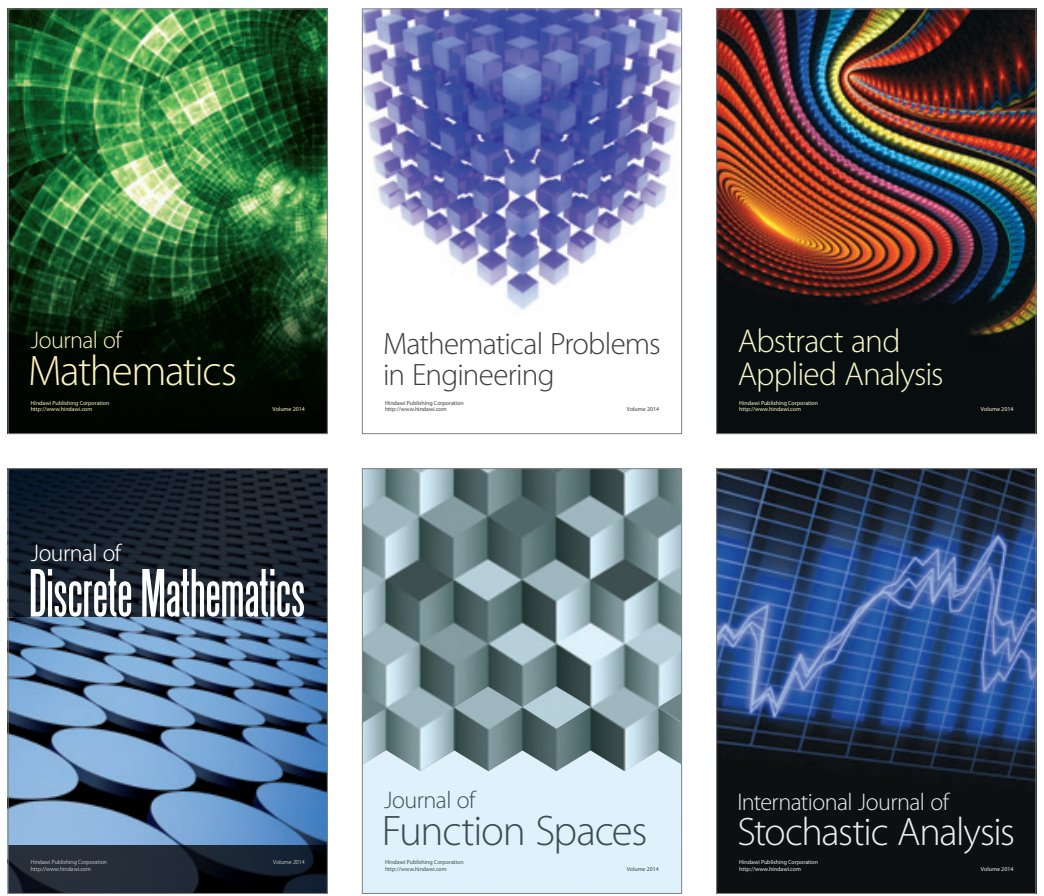

Journal of

Function Spaces

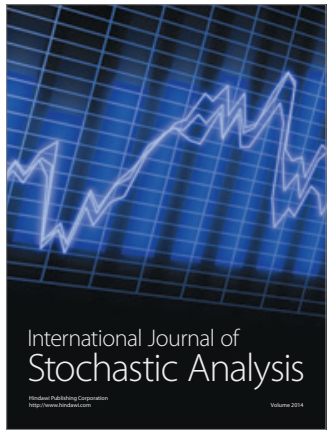

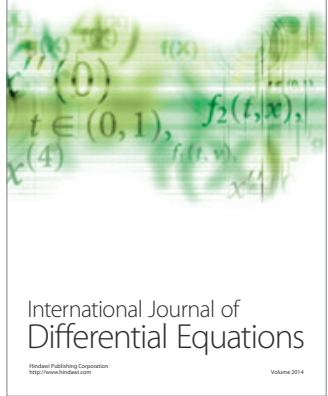
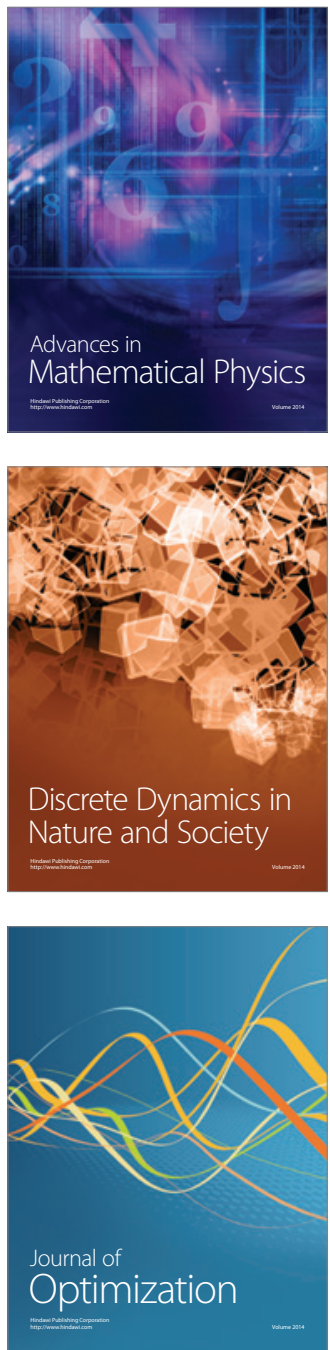